\title{
O novo desenvolvimentismo: uma contribuição institucionalista
}

The new developmentalism: an institutional contribution

HERTON CASTIGLIONI LOPES*

RESUMO: O trabalho objetiva analisar o novo desenvolvimento a partir da Teoria da Regulação (T.R.), do institucionalismo derivado de Veblen e da teoria evolucionária neoschumpeteriana. Demonstra que o novo desenvolvimento é uma instituição ao estabelecer uma regulação (formas institucionais) que considere as características estruturais dos países em desenvolvimento. Essa configuração macroeconômica, em conjunto com os hábitos mentais dos agentes, deve fortalecer as relações de mercado, os investimentos produtivos, a inovação e o progresso técnico. Este último deve acontecer a partir das oportunidades abertas pelas revoluções tecnológicas, permitindo o catching up das nações menos desenvolvidas (de renda média).

PALAVRAS-CHAVE: O novo desenvolvimentismo; escola da regulação francesa; institucionalismo de Veblen; neo-schumpeteriana.

ABSTRACT: The objective of this work is analyzing the New Developmentalism throughout the French Regulation School, Veblen's institutionalism and the Neo-Schumpeterian Approach. It aims to demonstrate, also, that the New Developmentalism is an institution when it establishes a regulation (institutional forms) that considers the structural characteristics of the developing countries. This macroeconomic configuration, together with the mental habits of the agents should strengthen the market relation, the productive investment, the innovation and the technical progress. This last one should happen through open opportunities in technological revolution, to let the 'catching up' of the nation less developed.

KEYWORDS: New Developmentalism; French regulation school; Veblen's institutionalism; Neo-Schumpeterian.

JEL Classification: E02; O11; O43; B52.

\footnotetext{
* Professor Adjunto da UFFS da Universidade Federal de Fronteira Sul - UFFS, e-mail: herton.lopes@ uffs.edu. Submetido: 7/Novembro/2014; Aprovado: 20/Outubro/2015.
} 


\section{INTRODUÇÃO}

Após a fase de industrialização por substituição de importações (nacional-desenvolvimentismo) e dos problemas de crescimento impostos pela ideologia neoliberal, uma série de autores, que tem Bresser-Pereira como principal expoente ${ }^{1}$, têm feito significativos esforços no sentido de desenvolver uma teoria que dê conta das atuais especificidades estruturais das economias latino-americanas. A proposta tem sido denominada "novo desenvolvimentismo", cujo adjetivo procura justamente explicitar as diferenças em relação ao período de crescimento que marcou o ingresso das economias periféricas à condição de países industrializados. De forma semelhante, se mostra como uma alternativa "radical" ao neoliberalismo, incapaz de garantir um crescimento sustentado das economias de industrialização atrasada. Por fugir aos objetivos dessa proposta e, evidentemente, pela dimensão textual, o trabalho não apresenta a distinção entre o novo desenvolvimentismo, o antigo desenvolvimentismo e a ortodoxia convencional, mesmo que algumas relações sejam feitas ao longo do texto ${ }^{2}$. Neste trabalho, objetiva-se contribuir com discussão que vem se estabelecendo, analisando o novo desenvolvimentismo enquanto modelo teórico a partir da integração de teorias institucionalistas/evolucionárias.

A importância da estratégia de desenvolvimento, assim como das instituições, não é novidade na literatura econômica. Chang (2002), por exemplo, demonstrou como as estratégias desenvolvimentistas e protecionistas foram importantes para os países desenvolvidos afirmarem-se como grandes potências. Bresser-Pereira (2006a, 2007) tratou de demonstrar que a estratégia nacional é a instituição-chave do crescimento, fazendo, inclusive, menção a noção de instituições de Douglass North $^{3}$, um dos autores modernos mais lembrados quando se trata da relação entre instituições e desenvolvimento. No texto em conjunto com Theuer, Bresser-Pereira retoma o conceito institucionalista de novo desenvolvimentismo, afirmando a necessidade de a estratégia nacional ser aceita pelos membros da sociedade, reduzir o conflito entre as classes e promover a coalizão social (Bresser-Pereira e Theuer, 2012). Recentemente, o reconhecimento do papel das instituições no processo de desenvolvimento deu origem a uma chamada especial da Revista de Economia Política. Nesse número, diversos autores contribuíram com estudos sobre o que consideravam ser a instituição fundamental do crescimento econômico.

A contribuição dos trabalhos foi significativa e oportuna. Eles têm proporcionado grandes avanços para compreensão da relação entre instituições e desenvol-

\footnotetext{
${ }^{1}$ Bresser-Pereira tem estado à frente do debate, com ideias esclarecedoras sobre a forma de relação entre Estado e Mercado, com uma estratégia de desenvolvimento que se aplique especialmente às economias de renda média ou que já superaram a etapa de substituição de importações.

${ }^{2}$ Para uma visão mais aprofundada sobre esses três “modelos" de desenvolvimento sugerem-se os textos de Bresser (2006b), Bresser e Gala (2010) e Bresser (2014b).

${ }^{3}$ Para uma melhor compreensão da teoria institucionalista de Douglass North sugerem-se as obras North (1990) e North (2005).
} 
vimento, especialmente quando o objeto são as nações de renda média. Contudo, diante da diversidade de correntes teóricas e do tratamento dado às instituições, novas formas de análise da estratégia nacional de desenvolvimento (e do novo desenvolvimentismo) vêm enriquecer o debate que se coloca em pauta. Com essa visão em mente, esse texto propõe-se a mobilizar, primeiramente, a Teoria da Regulação e o conceito de formas institucionais para analisar o novo desenvolvimentismo. Em seguida, utiliza o institucionalismo derivado de Veblen que oferece uma consistente e ampla definição de instituições. Finalmente, o catching up não pode ser compreendido sem uma teoria institucionalista que incorpore o progresso técnico. A esse respeito, a teoria neoschumpeteriana é incontestável na medida em que analisa as inovações no âmbito das firmas e as oportunidades que se abrem aos países em desenvolvimento quando da emergência de novas tecnologias e métodos de produção.

\section{TRÊS CORRENTES TEÓRICAS PARA CONSTITUIÇÃO DE UMA TEORIA INSTITUCIONALISTA DE ANÁLISE DO NOVO DESENVOLVIMENTISMO}

Instituições contam com uma série de definições que variam de acordo com a corrente teórica. Nessa proposta, o novo desenvolvimentismo e a estratégia nacional podem ser mais bem interpretados quando mobilizadas e unidas três correntes teóricas institucionalistas e de forte viés evolucionário. Primeiramente, admite-se a necessidade de fundamentos macroeconômicos para analisar como as políticas de estado afetam a forma de regulação, garantindo a acumulação de capital, o crescimento e amenizando os estrangulamentos que ocorrem do lado da demanda. $\mathrm{Na}$ sequência, toma-se emprestado da teoria de Veblen a definição de instituições e sua relação com os indivíduos, hábitos mentais e comportamento. Finalmente, mobiliza-se a teoria evolucionária neoschumpeteriana porque o sucesso de uma estratégia nacional como promotora do crescimento requer estímulos à inovação e ao progresso técnico como forma de os países em desenvolvimento alavancarem seus níveis de produtividade e criarem possibilidades de catching $u p$.

A teoria da regulação apresenta uma contribuição relevante para o trabalho na medida em que fornece um arcabouço teórico institucionalista que permite analisar como a configuração macroeconômica repercute sobre o crescimento. Seu estatuto teórico emerge com os problemas observados nos países avançados a partir dos anos 1970 (estagflação), desencadeando a necessidade de maiores estudos sobre as crises e regularidades pelas quais passam as economias capitalistas. Ao contrário da visão ortodoxa, autores dessa linha teórica compreendem o modo de produção como inerentemente instável, dotado de contradições e antagonismos que ocorrem devido à relação entre os homens. Em função disso, as instituições têm papel preponderante na reprodução do sistema porque são vistas como formas 
de mediação dos conflitos e antagonismos sociais ${ }^{4}$ (Conceição, 2005; Boyer, 1990). Como se observa, sua proposta teórica é altamente crítica à visão de ordem harmônica que prevalece nas relações de mercado, contrapondo-se ao individualismo metodológico e a ideia tradicional de racionalidade, procurando, ao mesmo tempo, demonstrar como as estruturas sociais se articulam com os indivíduos e seu comportamento ${ }^{5}$.

A teoria da regulação reconhece que cada sociedade é formada por um conjunto de estruturas, que emergem de um processo histórico de relações sociais, e captam as regularidades do plano dos indivíduos e as transportam ao plano macroeconômico. Trata-se das formas institucionais, entendidas como um nível intermediário de análise que se situa entre o regime de acumulação e o conceito de regulação (Boyer, 1990; Faria, 2001). O regime de acumulação é o “[...] conjunto de regularidades que asseguram uma progressão geral e relativamente coerente da acumulação de capital, ou seja, que permitem absorver ou repartir no tempo as distorções e desequilíbrios que surgem permanentemente ao longo do próprio processo" (Boyer, 1990, p. 72). Já um modo de regulação é um conjunto de mediações institucionais e organizacionais que mantém as distorções produzidas pela acumulação de capital nos limites compatíveis com a coesão social (Aglietta, 1976). Enquanto o regime de acumulação consiste na instância mais agregada das regularidades do sistema, o modo de regulação é a mais desagregada à medida que sanciona as normas e regras de conduta dos agentes. Entre uma noção e outra estão as formas institucionais. Assim, existem características específicas em um regime de acumulação definidas a partir das relações sociais e as formas institucionais são instância de ligação entre os dois níveis.

A noção de forma estrutural, segundo Boyer (1990, p. 73) “[...] tem o objetivo de elucidar a origem das regularidades que direcionam a reprodução econômica ao longo de um período histórico dado", sendo definida pelo autor como "[...] toda codificação de uma ou várias relações sociais fundamentais”. Além de importantes para analisar o crescimento a partir do modo de produção estabelecido historicamente, as formas institucionais são a instância de ligação entre os níveis micro e

\footnotetext{
${ }^{4}$ Conforme Bruno (2004, p. 18), em termos estritamente econômicos, a teoria da regulação procura expressar "[...] o modo como um processo essencialmente contraditório - o processo de acumulação de capital - consegue reproduzir-se com um grau suficientemente inteligível de regularidade [...]”.

${ }^{5}$ Assim como critica a ordem natural e a ideia de mercado autorregulado, discorda também da visão estruturalista fechada, onde os agentes e seus comportamentos são determinados pelas estruturas sociais, mantendo-se reféns do movimento das forças produtivas. (Boyer, 2003; Bruno, 2004). Os regulacionistas propõem uma síntese crítica das diferentes metodologias utilizadas na economia. Em primeiro lugar, tem-se o individualismo metodológico, no qual os agentes com suas predisposições naturais determinam as estruturas. Em segundo lugar, tem-se a visão estruturalista fechada (coletivismo metodológico), na qual as estruturas (a sociedade) determinam os comportamentos dos indivíduos. Enfim, a síntese representa a visão estruturalista aberta (ou holindividualismo metodológico), em que as estruturas canalizam, em períodos de estabilidade institucional, as práticas dos grupos ou dos indivíduos. Contudo, nos períodos de crise, tem-se uma inversão de causalidade. Um processo em que os indivíduos, por sua não conformidade com o ambiente instável, acabam por modificar as instituições (Bruno, 2004).
} 
macroeconômico. São elas: a forma estado, a relação salarial, a forma de inserção do país no regime internacional, a gestão monetário-financeira e a forma concorrência.

$\mathrm{Na}$ T.R., a forma estado ganha destaque dependendo de sua relação com o funcionamento do sistema econômico. Para Boyer e Saillard (2002), expressa a maneira de relacionamento da organização pública com a atividade econômica. Importante observar que o estado pode assumir duas posturas, que o caracterizam como "inscrito" na atividade econômica ou "circunscrito" a ela. No primeiro caso, assume papel ativo como formulador de políticas direcionadas ao crescimento. No segundo, fica refém das relações de mercado, participando apenas como coadjuvante, uma vez que a supremacia nas decisões econômicas fica por conta do sistema de preços. A forma welfare state, que surge a partir da Segunda Guerra é um exemplo de estado inscrito na atividade econômica e que tornou possível um estágio de forte crescimento, tradicionalmente conhecido como Anos Dourados. O estado do bem-estar traz consigo uma série de compromissos sociais que incluem, além de uma regulação macroeconômica consistente, políticas educacionais, de emprego, de renda, etc. (André, 2002). Nos regulacionistas ainda é possível observar dois tipos de política econômica. A política macroeconômica de regime (momento de estabilidade) atua como uma peça do modo de regulação vigente e surge, junto às formas institucionais, como instrumento suplementar de coordenação do nível micro para o macro. Por outro lado, a política econômica de transição de regime trata de utilizar o poder do Estado para promover ou acelerar a mutação das outras formas institucionais para superação da crise e gestação de um novo modelo de acumulação.

Dessa forma, a postura assumida pelo estado e sua política econômica se reflete na configuração das demais formas institucionais. A relação salarial, que trata da forma de apropriação do excedente da atividade econômica (Boyer, 1990), pode ser modificada a partir da ação do estado sobre o conjunto legal de condições institucionais que regulamentam o uso do trabalho assalariado (Boyer, 2002). No período fordista, por exemplo, foi essa forma de regulação que garantiu demanda para a revolução produtiva em curso e proporcionou uma repartição mais igualitária do excedente entre lucros e salários (produção em massa e consumo em massa). O crescimento se torna mais equilibrado quando o estado se propõe a viabilizar uma repartição mais justa do excedente, criando mercado de consumo para a gama de produtos oriundos dos ganhos de produtividade decorrentes da evolução das forças produtivas.

Não menos importante é a gestão financeira, pois se refere às características do sistema monetário e como o mesmo se inter-relaciona com as finanças internacionais. Deve ser afetado pelo estado a partir de uma diversidade de regulamentações que partem das autoridades monetárias e atingem de forma generalizada as instituições financeiras do país. A gestão monetária, assim como a relação salarial, aproxima a teoria da regulação da keynesiana (pós-keynesiana) ao demonstrar a necessidade de políticas de demanda para um crescimento sustentado. Como defendem esses autores, a moeda não apresenta características de neutralidade. Pelo 
contrário, é um ativo fundamental e diretamente relacionado à atividade econômi$\mathrm{ca}^{6}$. Nesse ponto, uma grande contribuição da escola regulacionista é exatamente compreender a moeda como uma instituição social ${ }^{7}$ (Guttmann, 2002).

Se a forma relação salarial e gestão monetário-financeira se mostra relevante para a forma de desenvolvimento das nações, o que dizer sobre a inserção do país no regime internacional e a forma de concorrência? A primeira trata da conjunção de regras que delimitam as relações entre os estados nacionais e o resto do mundo. Diz respeito às relações de trocas de mercadorias (localização da produção) e aos vínculos financeiros do país. Nos dias atuais, caracteriza claramente a opção do estado por políticas mais desenvolvimentistas ou atreladas à ideologia neoliberal. Por seu turno, a forma de concorrência pode ser identificada a partir de inúmeras variáveis, tais como o tamanho do produto, a escala das companhias, as relações envolvidas entre as empresas nos diferentes estágios do processo, a relação entre compradores e vendedores, etc. (Hollard, 2002). Refere-se aos estímulos para concorrência ou preservação de monopólios/oligopólios. Assim como as demais formas institucionais, pode ser modificada com políticas macroeconômicas ou setoriais de estímulo à concorrência ou concentração e centralização do capital.

É interessante notar que as formas institucionais refletem, além da opção estratégica do estado, uma série de regras que interferem no comportamento dos indivíduos. Se a forma de regulação estabelecida não estiver de acordo com o que esperam os agentes, no plano microeconômico desencadeiam uma crise que pode se manifestar em estagnação econômica. Justamente em função da necessidade das formas institucionais interagirem com o padrão comportamental dos agentes que o institucionalismo derivado de Veblen ganha relevância. Nesse autor, quaisquer instituições devem estar ancoradas em hábitos compartilhados de pensamento (Veblen, 1899, 1919) sob pena de se dissolverem. Por isso, o modo de regulação deve expressar as regras, as convenções e os padrões de ação dos agentes sociais8.

Hodgson $(2006,2007 b, 2010)$ é categórico ao afirmar que os hábitos são o alicerce de qualquer instituição social e representam as pré-disposições ou propensões das pessoas para agirem de determinada forma. São "an acquired proclivity or capacity, which may or may not be actually expressed in current behavior"

\footnotetext{
${ }^{6} \mathrm{Na}$ teoria pós-keynesiana a moeda não é neutra nem no curto nem no longo prazo, pois é reconhecida como um ativo especial que liga passado, presente, futuro e, o mais importante, ganha a preferência dos agentes (Arestis, 1992). Ela possui particularidades que a tornam um elemento especial de uma economia capitalista. No capítulo 17 da Teoria Geral é possível observar que a moeda é um ativo que se diferencia dos demais devido às suas propriedades, que são: elasticidade de produção zero (não é produzida por trabalho humano) e elasticidade de substituição zero (outros ativos não podem ser utilizados como moeda porque nenhum outro exerce a função de unidade de conta, meio de troca e reserva de valor) (Keynes, 1936).

${ }^{7}$ O destaque na tradição monetária regulacionista fica por conta de Aglietta e Orleans (1990). Na obra A Violência da Moeda os autores observaram que essa forma institucional apresenta tendência de se sobrepor às demais.

${ }^{8}$ Não por acaso, Bruno (2004) afirma a convergência entre o institucionalismo de Veblen e a Teoria da Regulação.
} 
(Hodgson, 2004, p. 652). A habituação é um processo que evoluiu historicamente, permitindo respostas mais rápidas diante dos problemas que se apresentam na sociedade. Assim, amenizam as limitações do cérebro humano em um ambiente altamente complexo como o nosso. Por isso, as instituições tem o papel fundamental de reduzir a incerteza ${ }^{9}$ e permitir comportamentos socialmente aceitos (Conceição e Ferrari Filho, 2005). Avançando no estudo dos hábitos, Hodgson (2007b) propõe que as instituições são um sistema de regras sociais e os hábitos são o elemento-chave no entendimento de como as regras são enraizadas em nosso cotidiano, mantendo as estruturas de funcionamento da sociedade.

As instituições, ao estarem alicerçadas nos hábitos, são uma propriedade emergente dos indivíduos e ambos (instituições e indivíduos) estão em constante interação e evolução. Não existe, porém, um único sentido de causalidade, seja dos indivíduos para as instituições, ou das instituições para os indivíduos. Nesse raciocínio, duas perspectivas teóricas vêm sendo criticadas por adeptos do antigo institucionalismo derivado de Veblen. Enquanto o individualismo metodológico ( $1^{\mathrm{a}}$ perspectiva) explica a emergência institucional a partir de indivíduos dados e imutáveis (com preferências homogêneas), o coletivismo metodológico ( $2^{\mathrm{a}}$ teoria) trata o comportamento dos agentes como dependente das estruturas sociais (instituições). Um meio-termo entre essas duas visões extremas é defendido por Hodgson (2011, p.1 $)^{10}$ ao propor o conceito de reconstitutive downward effect. Ele demonstra que existe uma relação de reciprocidade entre os agentes e as instituições. As instituições afetam o comportamento e as crenças dos indivíduos, mas estes exercem sua influencia sobre o sistema de regras a partir da sua habituação.

Finalmente, admitimos que a configuração das formas institucionais e o processo de habituação repercute diretamente no setor produtivo e na forma como acontece a inovação e o progresso técnico em qualquer economia. Esse entendimento remete à Schumpeter e aos autores neoschumpeterianos, que interpretam o desenvolvimento a partir de uma abordagem evolucionária e crítica à tradicional visão de equilíbrio neoclássica que não consegue explicar o crescimento e a mudança econômica/institucional. Nesse caso, duas abordagens neoschumpeterianas são

\footnotetext{
${ }^{9}$ De forma geral, os institucionalistas reconhecem as limitações do cérebro humano e a complexidade do ambiente, o que leva a incertezas na tomada de decisão. A esse respeito, Hodgson (2010) é categórico ao afirmar que a ação dos agentes é muito mais influenciada pelos hábitos (instituições) do que dependente de uma racionalidade substantiva que leve à maximização dos resultados. Em sua visão, a própria racionalidade sofre influência das instituições e do processo de habituação dos agentes.

${ }^{10}$ Não é apenas Hodgson que questiona essas visões extremadas, pois ela está presente nos diversos autores adeptos do institucionalismo de Veblen. Rutherford (2004), por exemplo, apresenta a mesma ideia de interação e determinação mútua entre agentes e instituições. Para o autor, a estrutura de funcionamento da sociedade está definida em suas instituições, que são um conjunto de regras determinadas a partir dos indivíduos. Uma vez que as instituições são estabelecidas a partir de hábitos comuns, criam-se e reforçam-se as estruturas de sustentação da sociedade. Da dinâmica entre instituições e hábitos provêm os comportamentos sociais que no setor produtivo definem as potencialidades econômicas.
} 
de grande relevância para a proposta deste trabalho: a teoria microeconômica evolucionária e a ideia de revoluções tecnológicas, com seus desdobramentos.

$\mathrm{Na}$ teoria microeconômica as decisões (e a dinâmica do processo produtivo) são guiadas por rotinas e as firmas com métodos de produção mais adequados às condições de mercado serão aquelas com maior chance de sucesso (Nelson e Winter, 1977, 1982). Nesse caso, as rotinas se apresentam com papel semelhante ao desempenhado pelos hábitos na sociedade porque dizem respeito a formas relativamente estáveis de fazer as coisas dentro da organização. Hodgson (2009) afirma que as rotinas são disposições organizacionais porque definem padrões de comportamento dentro de um grupo organizado de indivíduos. Como os hábitos, as rotinas passam por um processo evolucionário de seleção e adaptação e se tornam relativamente estáveis. Contudo, perante algumas circunstâncias é necessária a criação de novas rotinas, o que demanda inovação.

A inovação é de suma importância para o desenvolvimento porque é capaz de adequar ou criar técnicas produtivas. A capacidade para inovação resulta de um processo de aprendizagem (Zawislak, 1996) e proporciona a criação de novos métodos para viabilizar a solução dos problemas que acometem o processo produtivo. Em outras palavras, as rotinas desenvolvidas pelas firmas podem ser vistas como seu conjunto de técnicas que, quando postas à prova por determinados tipos de problemas, são alteradas ${ }^{11}$ (mutação) a partir de um processo inovativo. Dessa forma, a inovação altera as rotinas e as técnicas procurando melhorar as condições produtivas e permitindo a sobrevivência das firmas às condições de mercado.

É importante pontuar que, para os países em desenvolvimento, a análise evolucionária deve considerar os aspectos macroeconômicos da inovação e do progresso técnico. Além da configuração das formas institucionais, é preciso ter em mente que as grandes inovações tecnológicas não acontecem nesses países e, exatamente por isso, as condições de crescimento vão ser determinadas pelas chances de serem apropriadas as tecnologias que surgem nos países avançados. Em outras palavras, enquanto existem países líderes em termos tecnológicos, outros são seguidores (Abramovitz, 1986) e é preciso compreender por que algumas nações avançam (forging ahead) e alcançam os países desenvolvidos (catching up) enquanto outras são ultrapassadas (falling behind) e não conseguem alavancar seus níveis de produtividade. A esse respeito, a ideia de revoluções tecnológicas se torna estratégica para interpretar o crescimento na medida em que abre oportunidades para os países de renda média alcançarem os desenvolvidos.

O termo "revolução" não é utilizado por acaso. Toda configuração produtiva é alterada quando ela se desencadeia. Uma revolução tecnológica é "un poderoso y visible conjunto de tecnologías, productos e industrias nuevas y dinámicas, ca-

\footnotetext{
${ }^{11}$ Dosi $(1988$, p. 6) trata a inovação tecnológica como a "solução de problemas - por exemplo, a transformação de calor em movimento, moldar materiais de determinada maneira, produzir componentes com certa propriedade - satisfazendo, ao mesmo tempo, certos requerimentos de custo e comerciabilidade".
} 
paces de sacudir los cimientos de la economía y de impulsar una oleada de desarrollo de largo plazo" (Pérez, 2004, p. 32). Esta revolução passa por duas etapas distintas: um intervalo de instalação e outro de desprendimento, cada qual durando cerca de 20 ou 30 anos. O primeiro intervalo subdivide-se em dois períodos: um de irrupção, quando acontece um grande salto na produtividade das tecnologias relacionadas ao novo paradigma produtivo e outro chamado de frenesi, quando o comportamento frenético do capital financeiro, em busca de lucros associados a novas tecnologias, faz surgir bolhas financeiras. Com a crise aparece a necessidade de regulamentação estatal e reestruturação institucional, que gera um intervalo de acomodação abrindo possibilidades para uma segunda etapa: a de desprendimento ou difusão que se subdivide em uma fase de sinergia, com expansão do potencial inovativo e de mercado e uma fase de maturidade, com oportunidades de investimento decrescentes e capital ocioso que se movimenta em busca de maiores lucros.

Até o momento vivenciamos cinco revoluções: a revolução industrial; a era do vapor e das ferrovias; a era do aço e da eletricidade; a era do automóvel e da produção em massa; e a era da informática e da sociedade do conhecimento (revolução atual). Elas alteraram o modo de produção e as condições de desenvolvimento dos países no mundo inteiro. As revoluções tecnológicas e as novas tecnologias a ela associadas, as novas indústrias e infraestrutura decorrentes definiram ainda um novo paradigma tecnoeconômico. Para Conceição (2001), o paradigma incorpora a dimensão técnica, econômica e institucional que afeta as inovações e o progresso tecnológico. O paradigma é um roteiro para inovação, fornecendo um guia para a decisão dos empresários, inovadores, gerentes, administradores e investidores em busca da maior eficiência (Pérez, 2001, 1983, $2009)^{12}$. Importante é frisar que a revolução e o novo paradigma em curso abrem janelas de oportunidade aos países em desenvolvimento e o catching up fica dependente da trajetória tecnológica desencadeada pela nova fase de desenvolvimento. Nesse caso, quanto antes os países emergentes apropriarem-se das novas tecnologias, maiores suas chances de diminuir a diferença de produtividade em relação aos países de ponta ${ }^{13}$.

\footnotetext{
12 Atualmente vivenciamos o paradigma das redes flexíveis, que substituiu o paradigma da produção em massa ao pautar-se pelo uso intensivo da informação e da microeletrônica, definindo uma nova estrutura organizacional para empresas e um novo roteiro para inovação, baseado nas tecnologias da informação. Mais detalhes podem ser encontrados em Pérez (2004).

${ }^{13}$ Uma trajetória tecnológica se divide em quatro fases. Na primeira delas acontece uma inovação radical e o aparecimento de um novo produto que sustenta o desenvolvimento de uma indústria. $\mathrm{Na}$ segunda e terceira, as novas tecnologias passam por uma sequência de inovações incrementais, visando melhorar a qualidade, a produtividade e a posição dos produtores no mercado. Enfim, na quarta fase a tecnologia entra em maturação, com a inovação e a utilização das tecnologias já amplamente difundidas, reduzindo as possibilidades de lucro empresarial (Pérez e Soete, 1988; Pérez, 2001, 2004) e as chances dos países em desenvolvimento alcançarem os de ponta.
} 


\section{O NOVO DESENVOLVIMENTISMO A PARTIR DAS CONTRIBUIÇÕES INSTITUCIONALISTAS}

Pelo exposto, uma análise institucionalista do novo desenvolvimentismo requer que seja considerada a configuração macroeconômica que a teoria da regulação demonstra ser a chave para a compreensão dos períodos de prosperidade e crise vivenciados pelas economias capitalistas. Ao estado cabe o papel fundamental de articular o modo de regulação a partir de uma estratégia nacional que permita manter a coesão social e a acumulação de capital mesmo diante das contradições presentes no modo de produção capitalista.

No âmbito macroeconômico, a estratégia deve articular uma configuração das formas institucionais considerando não apenas as possíveis tensões que surgem das relações de produção, mas também as características estruturais dos países de renda média. Quanto à inserção do país no regime internacional, deve considerar as especificidades dos países emergentes em relação à concorrência e aos fluxos financeiros, que têm se mostrado extremamente comprometedores na condição de livre mercado. Ao contrário do que o neoliberalismo tem procurado demonstrar, num momento em que a globalização financeira e produtiva são irreversíveis, o papel dos estados nacionais assume relevância cada vez maior, justamente pela necessidade de políticas de desenvolvimento capazes de potencializar as chances das nações menos desenvolvidas alcançarem as de ponta (Bresser-Pereira, 2010; Bresser e Theuer, 2012).

Um dos debates mais frutíferos quando considerada a relação dos países de renda média com o resto do mundo se refere ao preço básico que define suas transações no mercado externo: a taxa de câmbio. O novo desenvolvimentismo observa que a competitividade das indústrias dos países em desenvolvimento tem sido prejudicada pela tendência cíclica de sobrevalorização da taxa de câmbio no longo prazo, que tem desestimulado a demanda efetiva, as expectativas de lucro e as oportunidades de investimento. O fenômeno ocorre devido à doença holandesa (problema estrutural) ${ }^{14}$, à atração de poupança externa ${ }^{15}$, às tentativas de controle da inflação através do câmbio e aos juros altos (problemas de política econômica) (Bresser-Pereira e Gala, 2010; Bresser-Pereira, 2011; Bresser-Pereira, 2014b). Agindo sobre a forma de regulação, o estado deve neutralizar o efeito da doença holandesa através de uma taxação das exportações ou uma tarifa de importações; que mova a taxa de câmbio do equilíbrio corrente para o equilíbrio industrial (Bresser-

\footnotetext{
${ }^{14}$ Para Bresser-Pereira e Gala (2010), a doença holandesa é representada pela sobreapreciação "crônica da taxa de câmbio", causada pela exploração de recursos naturais abundantes e baratos, gerando rendas ricardianas que valorizam a moeda nacional e impedem a competitividade das indústrias que seriam eficientes na ausência desse problema.

${ }^{15}$ Estudos que se pautam pela proposta novo desenvolvimentista demonstram que a poupança externa não é capaz de aumentar os investimentos e a criar um crescimento sustentável. O fluxo de recursos causa apenas endividamento externo, instabilidade financeira e pouco afeta os níveis de investimentos. Tais confirmações podem ser encontradas em Bresser-Pereira e Gala (2007) e Bresser-Pereira (2014).
} 
-Pereira, 2014b $)^{16}$. Além de estratégias para neutralizar a doença holandesa, o estado deve ser forte e autônomo o suficiente para repudiar as recomendações políticas que provêm dos países desenvolvidos, corrigindo as distorções presentes na forma de inserção do país no regime internacional e que prejudicam sua capacidade competitiva internacional.

Intimamente atrelada à forma de relação do país com o resto do mundo e a determinação da taxa de câmbio está a gestão monetário-financeira. A estratégia nacional de desenvolvimento deve procurar uma configuração financeira que estimule o pleno emprego de recursos, mobilizando a política monetária principalmente nos períodos de baixo crescimento. Embora o novo desenvolvimentismo priorize menor tolerância com a inflação, afirma a necessidade de juros relativamente mais baixos que os atualmente praticados nos países de renda média (Bresser-Pereira, 2014a). Junto com a correta determinação da taxa de câmbio, a gestão monetária menos restritiva irá criar um ambiente propício aos investimentos produtivos, ao crescimento econômico e à geração de poupança interna, que elimina a necessidade de fluxos financeiros e a decorrente vulnerabilidade das economias em desenvolvimento.

Outro problema para os países de renda média é a adequada regulamentação dos salários e a distribuição de renda. Segundo Bresser-Pereira (2014b), na proposta do novo desenvolvimentismo, políticas que visam corrigir o problema cambial podem ser prejudiciais a alguns rendimentos no curto prazo, inclusive os salários podem perder poder de compra devido à depreciação da moeda nacional. No longo prazo, contudo, as maiores oportunidades de investimento, decorrentes de uma taxa de câmbio competitiva e da gestão monetário-financeira adequada, tendem a proporcionar altas taxas de crescimento. Com o aumento da renda nacional é possível praticar estratégias consistentes de redução das desigualdades, que podem ser obtidas sem populismo cambial, mas com políticas de salário mínimo, baixas taxas de juros e uma estrutura tributária progressiva (Bresser-Pereira, 2014b). Essas recomendações ainda revertem outro importante problema dos países em desenvolvimento: o excesso de mão de obra que leva à deterioração da renda dos trabalhadores (Bresser-Pereira e Gala, 2007). Portanto, assim como na teoria da regulação, no novo desenvolvimentismo a adequada repartição do excedente é fundamental para à reprodução do sistema. Isso evita conflitos que poderiam colocar que xeque a estratégia nacional de desenvolvimento, prejudicar a coalizão social e comprometer o próprio processo de produção. Por esse motivo, ao mesmo tempo em que a estratégia nacional de desenvolvimento é importante para o cres-

\footnotetext{
${ }^{16}$ Bresser-Pereira prevê a possibilidade de duas taxas de câmbio de equilíbrio: a de equilíbrio corrente e a de equilíbrio industrial. A primeira resulta da exploração dos recursos naturais e tende a ser sobreapreciada. A segunda é aquela que viabiliza a competitividade das indústrias nacionais quando estas utilizam a tecnologia no estado da arte mundial (Bresser-Pereira, 2010, 2014).
} 
cimento, este último é importante para que a estratégia se consolide. Sem crescimento, o excedente é reduzido e o conflito entre classes se intensifica ${ }^{17}$.

Feitas essas considerações, observa-se que as políticas macroeconômicas propostas pelo novo desenvolvimentismo podem ser compreendidas a partir do conceito de regulação e da adequada configuração das formas institucionais. Porém, a simples modificação no conjunto de regras que compõem as formas institucionais pode não se mostrar eficiente para um crescimento forte e sustentado. Então, o que é preciso para que o novo desenvolvimentismo se afirme como a instituição do desenvolvimento? Tanto a Teoria da Regulação como o antigo institucionalismo derivado de Veblen demonstram que a eficácia da configuração macroeconômica (formas institucionais) depende das políticas se enraizarem na sociedade (ou nos indivíduos). O conjunto de regras (formais ou informais), com as proposições de política econômica que se materializam na forma de regulação, devem guiar as ações dos agentes produtivos rumo ao que se considera mais apropriado em frente às condições estruturais do país. Ao mesmo tempo em que passam a ser referência para o comportamento dos agentes, a configuração macroeconômica deve ser garantida por compromissos sociais, convenções, regras ou procedimentos socialmente aceitos. Por isso, afirma Boyer $(1990,2003)$ que as formas institucionais devem ser a codificação de uma ou várias relações sociais fundamentais.

Dessa forma, o novo desenvolvimentismo se institui a partir de uma estratégia nacional (Bresser-Pereira, 2007). Porém, para que consolide como modelo de desenvolvimento, precisa encontrar respaldo no ambiente socioeconômico. Isso significa que o novo desenvolvimentismo deve propor uma configuração de formas institucionais que representem as regularidades no plano de atuação dos agentes. Essas regularidades se transportam para nível macroeconômico, representando a institucionalidade das relações que garantem a estabilidade do regime de acumulação ${ }^{18}$. Registre-se que trabalhos novo desenvolvimentistas têm avançado claramente nessa compreensão. Bresser-Pereira e Theuer (2012), por exemplo, reconheceram que novo desenvolvimentismo não é apenas um conjunto de políticas, mas uma estratégia de desenvolvimento nacional informal: uma instituição, entendida como a soma de valores, objetivos, políticas, leis, entre outros. Para ser a instituição

\footnotetext{
17 Oreiro (2012) sugere uma estratégia de desenvolvimento capaz de estabelecer uma regulação que vincule os aumentos reais de salários aos ganhos de produtividade, evitando conflitos e pressões inflacionárias.

${ }^{18}$ Ao criticar o conceito de racionalidade tradicional e propor o de racionalidade situada e procedimental, os regulacionistas superam a dicotomia entre agente-estrutura a partir da ideia de habitus provinda da antropologia. Bourdieu (1997) propôs que o agente social é dotado de um habitus "individual coletivo ou um coletivo individualizado". Assume que os indivíduos possuem características, preferências e gostos formados a partir da sua história e aprendizagem, tanto a coletiva como a individual. O habitus serve para compreender a ação humana, pois ela não depende de cálculos maximizadores. Trata-se de um princípio de ação que reduz a necessidade de esforços cognitivos e, portanto, o tempo de deliberação em determinadas circunstâncias.
} 
do crescimento, deve proporcionar entendimentos e compromissos que criam oportunidades de investimento e melhoram as condições de vida da população.

Indispensável, então, para a compreensão do novo desenvolvimentismo como instituição é a contribuição do conceito de reconstitutive donward effect proposto por Hodgson (2011) a partir da teoria de Veblen. A estratégia nacional de desenvolvimento deve ser incorporada aos hábitos mentais dos agentes e ser capaz de influenciar (definir) sua forma de pensar e agir. Deve se mostrar como um pensamento compartilhado, reduzindo a incerteza sobre os investimentos futuros e apontando o melhor caminho para a nação. Na medida em que se mostra eficiente, a estratégia passa a ser aceita pela sociedade, que reforça sua institucionalidade com comportamentos que passam a ser rotineiros. Satisfaz-se, assim, a condição de afirmação de uma instituição: indivíduos cunham instituições a partir dos hábitos compartilhados e as instituições, uma vez estabelecidas, definem ou estimulam determinadas condutas individuais. Se isso não acontecer, a estratégia pode entrar em decadência, pois ao não ser reforçada pelos hábitos e não se apresentar enraizada na sociedade, acaba comprometendo o desempenho da nação. A história já deu seus exemplos: quando a estratégia desenvolvimentista entrou em crise, acabou substituída pela ideologia neoliberal. Quando esta não foi capaz de promover o crescimento, uma nova configuração macroeconômica foi necessária.

Portanto, a estratégia não pode ser implantada do alto. É preciso que o conjunto de políticas que define o novo desenvolvimentismo tenha aderência microeconômica, seja aceito pela coletividade, esteja de acordo com as especificidades dos países em desenvolvimento e promovam um crescimento equilibrado. Assim será possível uma coalizão nacional e a integração dos diversos interesses de classes no objetivo de alcançar o desenvolvimento (Bresser-Pereira, 2006a; Bresser-Pereira, 2007; Bresser-Pereira e Theuer, 2012; Bresser, 2014b). Uma vez estabelecidas as regras macroeconômicas e as políticas de estado, a aceitação ou adesão dos agentes no plano individual permite aumentar os níveis de confiança dos empresários. Ou seja, a incerteza, tão enfatizada por autores pós-keynesianos, se reduz, as expectativas de lucros aumentam, os investimentos crescem, a renda real aumenta e a institucionalidade do novo desenvolvimentismo se afirma.

A constituição dessa forma de regulação, que emerge do estado a partir da sua estratégia nacional, é apresentada na figura a seguir. A estratégia de desenvolvimento deve partir de um Estado Forte, que forneça a infraestrutura necessária ao setor produtivo, garanta os preços macroeconômicos (taxa de câmbio competitiva, taxa de lucro adequada, menores taxas de juros, salários compatíveis com a taxa de lucro ${ }^{19}$ e inflação sob controle) e, dessa forma, fortaleça as relações de mercado, grande responsável pela alocação de recursos nos setores competitivos (Bresser-

\footnotetext{
${ }^{19}$ Bresser-Pereira (2014b) atesta que a imposição da escolha de uma estratégia profit-led ou wage-led não faz sentido porque tentar reduzir as desigualdades através da taxa de câmbio sobreapreciada é um erro. A desigualdade deve ser combatida por políticas de salário mínimo, de impostos progressivos e com maiores gastos sociais.
} 
-Pereira, 2014a). Para isso, o setor público deve evitar gastos ineficientes (keynesianismo vulgar que causa déficits fiscais crônicos) e estimular a evolução competitiva da indústria nacional, justamente para não minar sua própria capacidade financeira futura. A estratégia nacional, além de amenizar os problemas do lado da demanda, é responsável por incentivar a inovação, que surge a partir da atuação das firmas no mercado. A estas, o estado deve oferecer uma configuração macroeconômica adequada e incentivos diretos, com políticas específicas que promovam o avanço das técnicas produtivas. É importante observar que as firmas, assim como os demais atores sociais, podem fazer pressões para que a estratégia novo desenvolvimentista seja alterada. Desse fenômeno surge a mudança institucional (ou de modelo), que se inicia com a inconformidade dos agentes com a estratégia em curso, instaurando um processo de seleção e adaptação das políticas mais apropriadas ao crescimento.

Figura 1 - Novo Desenvolvimentismo como Instituição

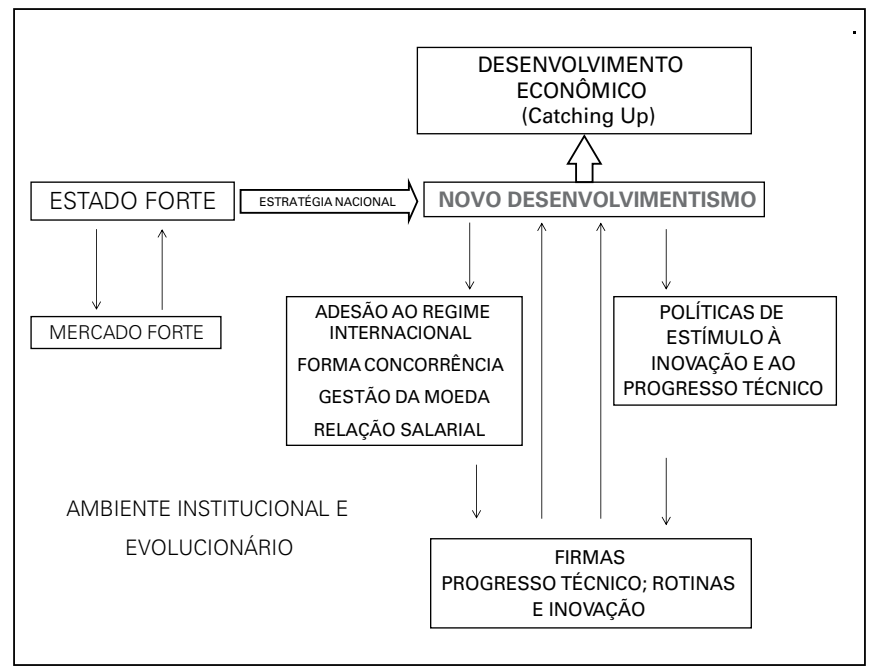

Fonte: Elaboração própria.

Visto com as propostas de política do novo desenvolvimentismo devem ser incorporadas à teoria da regulação e o que lhe confere característica de instituição, o plano das firmas merece maior destaque. Isso porque são elas as grandes responsáveis pela evolução da estrutura produtiva que permite os ganhos de produtividade, essência do desenvolvimento econômico. A união da teoria da regulação com a neoschumpeteriana, nesse caso, demonstra como as condições do lado da procura (interna e externa) evoluem a ponto de garantir a absorção dos frutos da inovação ${ }^{20}$. Coriat e Dosi (2007) afirmam que a regulação e o avanço tecnológico devem

\footnotetext{
${ }^{20}$ Isso não aparece como novidade contemporânea. Celso Furtado (1972), quando escreveu o modelo brasileiro, foi taxativo ao afirmar que o progresso técnico deve ser acompanhado por modificações na demanda efetiva.
} 
estar em sintonia para que o desenvolvimento econômico não seja comprometido. Em outras palavras, as formas institucionais devem estar adequadas para promover o crescimento sustentado, que acontece com acumulação de capital e progresso tecnológico ${ }^{21}$. Do contrário podem gerar instabilidade, crises e depressões macroeconômicas.

Sabe-se que progresso técnico é determinante para o catching up. Contudo, para que as nações de renda média diminuam as diferenças em relação às economias desenvolvidas é preciso que a estratégia nacional de desenvolvimento estimule uma inovação que, além de romper com as condições produtivas existentes (Schumpeter, 1942, 1911), deve acontecer nas primeiras fases da revolução tecnológica em curso. Isso porque a trajetória tecnológica demonstra a tendência da tecnologia se expandir para os países em desenvolvimento apenas quando as técnicas produtivas encontram-se em fase de maturação. Eis um grande desafio do estado: fazer políticas que ofereçam possibilidades de o país ingressar no novo paradigma tecnoeconômico no momento em que as inovações associadas às novas tecnologias apresentam maior rentabilidade. Além disso, nos períodos iniciais de uma revolução o conhecimento produtivo não é protegido por patentes e ainda está disponível ao público em órgãos de pesquisa e universidades ${ }^{22}$.

O progresso técnico é, ainda, altamente influenciado pela forma de concorrência (ou competitividade) estabelecida no mercado. A estratégia de estado deve fortalecer a competição, garantindo um ambiente de seleção para as empresas mais aptas incorporarem as inovações de ponta. Isso significa que no novo desenvolvimentismo o excesso de protecionismo não é a melhor opção dos países de renda média (que possuem uma estrutura industrial capaz de competir no mercado externo). Além da regulamentação da forma concorrência, o estado deve priorizar políticas industriais e setoriais de estímulos à inovação, aumentando as chances de apropriação do novo conhecimento produtivo, o que requer políticas de criação e fortalecimento de um adequado Sistema Nacional de Inovações (S.N.I. $)^{23}$. Nelson

21 Os exemplos são claros: a relação salarial afeta a repartição do excedente entre lucros e salários, estabelecendo a demanda para os produtos da revolução em curso. A forma concorrência cria os incentivos ao progresso tecnológico a partir do grau de competição observado nos mercados. A gestão monetária, ao incluir todo regime monetário-financeiro, traz repercussões significativas sobre os investimentos produtivos (visão pós-keynesiana) e a propensão à inovação. A relação do país com o exterior repercute de forma importante sobre as possibilidades de inovação e progresso tecnológico porque a inserção no regime internacional define os fluxos financeiros e de mercadorias entre as nações, afetando não apenas a gestão monetário-financeira, mas a forma competição no mercado interno.

${ }^{22}$ Cabe destacar, contudo, que as capacitações criadas antes da explosão de uma nova revolução são de suma relevância. Por isso, Pérez (1992) afirma que a fase de maturação de uma tecnologia, junto com a fase de surgimento das novas, é um momento de dupla oportunidade tecnológica.

${ }^{23}$ De acordo com a $3^{\text {a }}$ tese do novo desenvolvimentismo, o estado deve articular um sistema nacional de inovações "que capture oportunidades globais, isto é, economias de escala globais e fontes múltiplas de aprendizado tecnológico, reduza barreiras à inovação decorrentes de regimes de propriedade intelectual excessivamente rígidos, assegure estabilidade financeira e crie oportunidades de investimento para empreendedores privados”. 
(2007, p. 18) afirma que um S.N.I. compreende "the wide range of institutions that are involved in supporting and orienting the dynamics of economic activity where innovation is the key driving force". Entre elas estão um sistema financeiro forte (público e privado), uma educação primária e secundária adequada, universidades com formação de cientistas e engenheiros capazes de operar novas tecnologias, laboratórios públicos e privados de $\mathrm{P} \& \mathrm{D}$ e mecanismos de incentivo à cooperação entre firmas.

Diante dessas considerações fica clara a necessidade de um mercado forte. Um ambiente de seleção e adaptação onde as empresas com rotinas e tecnologias mais aptas devem sobreviver e se disseminar. Embora o progresso técnico possa ser desenvolvido no contexto de poucas firmas que são economicamente de "ponta", com o passar do tempo deve se propagar na economia em desenvolvimento criando novas tecnologias sociais, já que estas podem ser encaradas como a disseminação de práticas que permitem melhores condições produtivas. A esse respeito, registre-se a contribuição de Nelson e Sampat (2001) e Nelson (2008). Para os autores, as tecnologias sociais se referem a maneiras-padrão e esperadas de interação entre os agentes econômicos na busca de determinados resultados. Referem-se ao compartilhamento de rotinas a partir de um mercado forte, que permite a sobrevivência das melhores técnicas.

Quando se compreende a necessidade da estratégia nacional para os países em desenvolvimento fica claro por que a teoria neoliberal é tão defendida pelas nações avançadas. Ela garante, nos países periféricos, mercado para os artigos de uma revolução tecnológica. Enquanto a abertura comercial permite a livre entrada de mercadorias, a abertura financeira cria as condições de pagamento. Bresser-Pereira e Gala (2007) afirmam que os problemas de crescimento seriam menores nas nações menos desenvolvidas se a poupança externa contasse com oportunidades de investimento lucrativas. Contudo, sem uma estratégia de desenvolvimento, e uma vez estabelecido o paradigma tecnoeconômico, mesmo que o fluxo de recursos venha como investimento direto as tecnologias da revolução estarão protegidas por patentes ou em fase de maturação, já com poucas potencialidades de alavancar um catching up futuro.

Finalmente, se o neoliberalismo não se mostrou conveniente para as economias em desenvolvimento, historicamente foi capaz de trazer certa aprendizagem. $\mathrm{O}$ mesmo vale para o antigo desenvolvimentismo. Na proposta evolucionária das correntes neoschumpeteriana e vebleniana, o novo desenvolvimentismo vem se constituindo com uma vantagem significativa em relação ao antigo desenvolvimentismo e as políticas neoliberalizantes, pois teve muitos dos seus pressupostos testados por um processo evolucionário. $\mathrm{O}$ antigo desenvolvimentismo foi uma instituição que perdurou por diversos anos e trouxe significativas taxas de crescimento econômico. A crise dessa estratégia nacional de desenvolvimento permite que muitos erros não voltem a ser cometidos. O neoliberalismo, por sua vez, apresentou-se como alternativa ao desenvolvimentismo justamente porque este entrara em crise. Porém, a diversidade de ações ortodoxas não permitiu uma coesão social, prejudicando os investimentos produtivos, a acumulação de capital e o progresso técnico. 
Por isso, o novo desenvolvimentismo surge a partir de um processo evolucionário de seleção e adaptação. Adaptação das políticas mais consistentes do desenvolvimentismo e, ao mesmo tempo, seleção (e eliminação) das ações incoerentes impostas pela ideologia neoliberal.

\section{CONSIDERAÇÕES FINAIS}

Num momento em que o nacional-desenvolvimentismo e a ideologia neoliberal se mostram inadequados para promover o crescimento dos países latino-americanos e uma nova proposta de desenvolvimento emerge, este texto se propôs a uma importante contribuição teórica: analisar o novo desenvolvimentismo a partir de ideias provindas da Teoria da Regulação, do institucionalismo derivado de Veblen e da teoria neoschumpeteriana. Dessa forma, procurou contribuir com essa nova teoria com referenciais teóricos não ortodoxos e que se pautam pela preocupação de analisar o desenvolvimento com significativa presença do estado.

O novo desenvolvimentismo é uma estratégia de um estado forte que garante um mercado forte. É uma instituição que coloca em evidência uma série de regras que configuram as formas institucionais visando amenizar os problemas estruturais das economias emergentes. Essa configuração macroeconômica deve fortalecer as relações de mercado, os investimentos produtivos, a inovação e o progresso técnico, que deve acontecer a partir das oportunidades abertas pelas revoluções tecnológicas. Nesse aspecto, cabe frisar a contribuição atual deste trabalho, pois a quinta revolução está em pleno curso e as políticas desenvolvimentistas adotadas nesse momento serão fundamentais não apenas para o aproveitamento das tecnologias em evolução, mas para criar as condições necessárias ao catching up quando um novo paradigma tecnoeconômico emergir. $\mathrm{O}$ sucesso das nações de renda média ante uma nova revolução produtiva demandará uma intensa participação do estado tanto em políticas setoriais, como nos estímulos produtivos que provém da regulação macroeconômica.

Nessa perspectiva, a instituição novo desenvolvimentista é aquela que apresenta uma configuração macroeconômica que solucione os empecilhos do lado da demanda (debilidade de investimentos devido à tendência dos salários crescerem abaixo da produtividade e sobrevalorização da taxa de câmbio) e estimule a inovação e progresso técnico do lado da oferta. Contudo, para que isso seja possível, torna-se necessário que a estratégia constitua-se como um conjunto de regras com embasamento e respaldo nos hábitos mentais dos agentes, especialmente àqueles que atuam no plano produtivo. Os empresários inovadores devem gozar de um ambiente de confiança, o que depende de um clima macroeconômico e institucional adequado aos investimentos produtivos e progresso tecnológico.

No caso brasileiro, essa estratégia nacional é fundamental. A forma de inserção internacional, que pressupôs redução de barreiras comerciais e liberalização financeira, vem causando sérios prejuízos ao setor produtivo industrial nos últimos anos. A supremacia dessa forma institucional, que inclui uma gestão monetário-financei- 
ra restritiva, tem feito a indústria perder participação enquanto eixo central do crescimento ao mesmo tempo em que enfraquece o setor público e sua capacidade de colocar em prática uma estratégia capaz de superar o baixo dinamismo. Com a débil capacidade de inserção competitiva da indústria brasileira, a única forma de manter a equilíbrio externo é com altas taxas de juros, a entrada massiva de capitais de curto prazo e a exportação de produtos de baixo valor agregado (exploração de recursos naturais). Uma profunda mudança institucional, que rompa com essa forma de regulação, é precondição para superar a tradicional dinâmica de stop and go que nos assombra. Mesmo que as exportações primárias tenham sido historicamente importantes para o desempenho da economia brasileira, uma forma de regulação que estimule as exportações de maior conteúdo tecnológico é essencial. Para isso, a política econômica deve ainda romper com alguns interesses, tratando de reconfigurar essa regulação que se alicerça sobre uma acumulação rentista-patrimonial e beneficia setores exportadores de commodities em detrimento daqueles de maior conteúdo tecnológico. Essa seria uma questão-chave para políticas eficientes de distribuição de renda, pois o crescimento baseado apenas na demanda interna pode causar déficits crônicos em conta-corrente. Sem um setor industrial internacionalmente competitivo, esses desequilíbrios acabam prejudicando a possibilidade de um crescimento sustentável.

\section{REFERÊNCIAS BIBLIOGRÁFICAS}

ABRAMOVITZ, M (1986). "Catching up, forging ahead and falling behind". Journal of Economic History, v. 46, n. 2, p. 385-406.

AGLIETTA, M. (1976) Régulation et Crises du Capitalisme: L'expérience des États-Unis. Paris, Calmann-Lévy.

AGLIETTA, M.; ORLEANS, A (1990). A Violência da Moeda. São Paulo: Editora Brasiliense.

ANDRE, C (2002). "The welfare state and institutional compromises: from origins to contemporary crises”. In R.Boyer; Y. Saillard, orgs. Regulation Theory: The State of the Art. Paris : La Découverte \& Syros.

ARESTIS, P (1992). The Post-Keynesian Approach to Economics. Aldershot: Edward Elgar.

BOURDIEU, P (1997). "Le champ Économique”. Actes de la Recherche em Sciences Sociales, n¹19, Septembre.

BOYER. R (1986 [1990]). A Teoria da Regulação: Uma Análise Crítica. São Paulo: Nobel.

BOYER. R (2003) . Les Institutions dans la Théorie de la Régulation. CEPREMAP. Paris.

BOYER. R (2002). "Perspectives on the wage-labour nexus". In R.Boyer; Y. Saillard, orgs. Regulation Theory: The State of the Art. Paris : La Découverte \& Syros

BOYER, R; SAILLARD, Y (2002). "A summary of regulation theory”. In R.Boyer; Y. Saillard, orgs. Regulation Theory: The State of the Art. Paris : La Découverte \& Syros

BRESSER-PEREIRA, L.C (2010). "Taxa de câmbio, doença holandesa, e industrialização”. Cadernos FGV Projetos, 5 (14). P. 68-73.

BRESSER-PEREIRA, L.C. (2010). Globalização e Competição. Rio de Janeiro: Campus/Elsiever.

BRESSER-PEREIRA, L.C (2014a). “Macroéconomie développementiste”. Palestra no Institut des Amériques, Paris, 2014.

BRESSER-PEREIRA, L.C (2011). “O Brasil e o novo desenvolvimentismo”. Interesse Nacional.

BRESSER-PEREIRA, L.C (2014b). "Reflecting on New Developmentalism”. São Paulo, EESP/FGV. 
BRESSER-PEREIRA, L.C (2006a) "Estratégia nacional e desenvolvimentismo". Revista de Economia Política, vol.26 n ${ }^{\circ} 2$ (102), p.203-230.

BRESSER-PEREIRA, L.C (2007). “Estado e mercado en el nuevo desarrolismo". Revista Nueva Sociedad, $\mathrm{n}^{\circ} 210$, julho-agosto.

BRESSER-PEREIRA, L.C (2006b). “O novo desenvolvimentismo e a ortodoxia convencional.” Revista São Paulo em Perspectiva, v. 20, n. 3, jul/set, p. 5-24.

BRESSER-PEREIRA, L.C .(2007). "National development strategy: the key economic growth institution”. Textos para discussão da Escola de Economia de São Paulo.

BRESSER-PEREIRA, L.C; GALA, P (2010).”Macroeconomia estruturalista do desenvolvimento". Revista de Economia Política. vol. 30, $\mathrm{n}^{\circ} 4$ (120), pp. 663-686.

BRESSER-PEREIRA, L.C; GALA, P (2007). "Por que a poupança externa não promove crescimento". Revista de Economia Política, vol.27, n.1, pp. 3-19.

BRESSER-PEREIRA, L.C; THEUER, D (2012). "Um estado novo desenvolvimentista na América Latina?” Revista Economia e Sociedade, vol. 21, número especial. P. 811 -829.

BRUNO, M. A. P (2004). "Crescimento econômico, mudanças estruturais e distribuição as transformações do regime de acumulação no Brasil: uma análise regulacionista”. Tese (Doutorado em Economia) - Universidade Federal do Rio de Janeiro, Rio de Janeiro.

CHANG, Ha-Joon (2002). Kicking Away the Ladder: Development Strategy in Historical Perspective. London: Anthem Press.

CONCEIÇÃO, O. A (2001). Instituições, Crescimento e Mudança na Ótica Institucionalista. Porto Alegre: Fundação de Economia e Estatística Siegfried Emanuel Heuser (FEE).

CONCEIÇÃO, O. A. C. ; FERRARI FILHO, F (2005) . "The concept of uncertainty in Post Keynesian theory and in institutional economics". Journal of Economic Issues, v. 34, n.3, p. 579-594.

CONCEIÇÃO, O. A. C (2005). "O conceito de instituição nas modernas abordagens institucionalistas." In Encontro Nacional de Economia Política, 7, 2005, Curitiba. Anais do VII Encontro Nacional de Economia Política. Disponível em: <http://www.sep.org.br/artigo/7_congresso_old/CONCEICAO_OCTAVIO.pdf $>$. Acesso em: 10 mar. 2011.

CORIAT, B; DOSI, G (2007). The institutional embeddedness of economic change: an appraisal of the 'evolutionary' and 'regulationist' research programmes. Disponível em http://esnie.org/pdf/textes_2007/Dosi-chap-12.pdf. Acesso 17 de jul. de 2013

DOSI, G (1988). “Sources, procedures and microeconomic effects of innovation”. Journal of Economic Literature, 26 (3) 1120 - 1171.

FARIA. L. A. E (2001). "As formas institucionais de estrutura: do micro ao macro na teoria da regulação”. Ensaios FEE, Porto Alegre, v. 22, n. 1, p. 187-204.

FURTADO, C (1972). Análise do Modelo brasileiro. Civilização Brasileira: Rio de Janeiro.

GUTTMANN, R . (2002). "Money and credit in regulation theory". In R. Boyer; Y.Saillard, orgs. Regulation Theory: The State of the Art. Paris : La Découverte \& Syros.

HODGSON, G. M (2011). Downward causation - some second thoughts. Watford (UK). Disponível em: <http://www.geoffrey-hodgson.info/downward-causation.htm>. Acesso em: 26 ago. 2011

HODGSON, G. M (2006). "What Are Institutions?” Journal of Economic Issues. Vol. XL No. 1. p. $1-25$.

HODGSON, G. M (2004). "Reclaiming habit for institutional economics". Journal of Economic Psychology. n 25. p. 651-660.

HODGSON, G. M (2010). “Choice, habit and evolution” Journal of Evolutionary Economics. 20(1), pp. $1-18$.

HODGSON, G. M (2007b). "Institutions and individuals: interaction and evolution". Organization Studies, v. 28, n. 1, p. 95-116.

HODGSON, G.M. (2009). “The nature and replication of routines”. In M. C. Becker, N. Lazaric, orgs. Organizational Routines: Advancing Empirical Research, Cheltenham, U.K.: Edward Elgar: 2644.

HOLLARD, M (2002). "Forms of competition”. In R. Boyer; Y. Saillard, orgs.. Regulation Theory: The State of the Art. Paris : La Découverte \& Syros. 
KEYNES, J.M (1936 [1964]). The General Theory of Employment, Interest and Money. New York, Harcourt Brace.

NELSON, R (2008) "What enables rapid economic progress: what are the needed institutions". Research Policy, N. 37, p. 1-11

NELSON, R. (2007). "Economic development from the perspective of evolutionary economic theory". Working paper series Globelics.

NELSON, R. R.; SAMPAT, B.N (2001). "Las instituiciones como factor que regula el desempeño econômico". Revista de Economia Institucional, v.2 nº 005. Bogotá: Colômbia, p 17-51.

NELSON, R.; WINTER, S. G (1977). "In search of useful theory of innovation”. Research Police. Elsevier, vol. 6(1), pages 36-76.

NELSON, R.; e WINTER, S. G. (1982 [2005]) . Uma Teoria Evolucionária da Mudança Econômica. Campinas, SP: Editora da Unicamp.

NORTH, D.C. (1990). Institutions, Institutional Change and Economic Performance. Cambridge: Cambridge University Press.

NORTH, D.C. (2005) Understanding the Process of Economic Change. Princeton/Oxford: Princeton University Press.

OREIRO, J. L. C (2012). “Novo-desenvolvimentismo, crescimento econômico e regimes de política macroeconômica”. Revista Estudos Avançados, Vol.26, n.75, pp. 29-40.

PEREZ, C. (1992). "Cambio técnico, restructuración competitiva y reforma institucional en los países en desarrollo". El Trimestre Económico, México, v. 1, n. 233, p. 23-64, enero/marzo.

PEREZ, C. (1983) "Cambio estructural y asimilación de nuevas tecnologías en el sistema económico y social: . Futures, Vol. 15, No 4, Octubre, pp. 357-375 (Tradução do ingles).

PEREZ, C (2001). “Cambio tecnológico y oportunidades de desarollo como Blanco móvil”. Revista de la CEPAL, Santiago de Chile, n. 75, p. 115-136.

PEREZ, C. (2004). Revoluciones Tecnológicas y Capital Financiero: La Dinâmica de las Grandes Burbujas Financieras y Las Épocas de Bonanza. México: Siglo XXI.

PEREZ, C. (2009). "Technological revolutions and techno-economic paradigms". Working Papers in Technology Governance and Economic Dynamics, no. 20..

PEREZ, C.; SOETE, L (1988). "Catching up in technology: entry barriers and windows of opportunity.” In G. Dosi et al.., org. Technical Change and Economic Theory. Laboratory of Economics and Management (LEM), Sant'Anna School of Advanced Studies, Pisa, Italy.

RUTHERFORD, M (2004). Institutions in Economics: The Old and the New Institutionalism. Cambridge: Cambridge University Press.

SCHUMPETER, J. A (1942 [1984]). Capitalismo Socialismo e Democracia. Rio de janeiro: Fundo de Cultura.

SCHUMPETER, J. A (1911 [1985]). A Teoria do Desenvolvimento Econômico. São Paulo: Nova Cultural.

TEN THESES ON NEW DEVELOPMENTALISM. . Disponível em http://www.tenthesesonnewdevelopmentalism.org. Acesso 30 de jun. de 2014

VEBLEN, T. (1899 [1983]). A Teoria da Classe Ociosa: Um Estudo Econômico das Instituições. São Paulo: Abril Cultural.

VEBLEN, T. (1919). The Place of Science in Modern Civilization and Other Essays. New York : Huebsch.

ZAWISLAK, P.A (1996). "Uma abordagem evolucionária para casos de atividade de inovação no Brasil”. Ensaios FEE. Porto Alegre, V. 17, nº1, p. 323-353. 